V. 13 N. 1

JAN-ABR 2017

ISSN 2317-6172

Recebido: 05.02.2015

Aprovado: 06.03.2017

DOI: http://dx.doi.org/10.1590/2317-6172201704

Universidade Federal de Juiz de Fora Juiz de Fora - MG - Brasil

2 Universidade Federal de Juiz de Fora Juiz de Fora - MG - Brasil

3 Universidade Federal de Juiz de Fora Juiz de Fora - MG - Brasil

\section{Robin Hood às avessas: software, pirataria e direito autoral}

ROBIN HOOD IN REVERSE: SOFTWARE, PIRACY AND COPYRIGHT

\author{
Marcos Vinício Chein Feres ${ }^{\mathbf{1}}$, Jordan Vinícius de Oliveira ${ }^{\mathbf{2}}$ \\ e Daniel Domingues Gonçalves ${ }^{3}$
}

\section{Resumo}

Como a pirataria influencia o mercado de programas de computador? A presente pesquisa visa analisar os efeitos respectivos da pirataria tanto para as grandes corporações quanto para os pequenos desenvolvedores de software. 0 plano teórico é composto pelas teorias de viver plenamente a lei e de luta por reconhecimento. A análise do tipo qualitativa é atingida por meio do método das regras de inferência. Os principais resultados são de que as leis de propriedade intelectual acabam por viabilizar o monopólio de mercado em vez da inovação competitiva e de que a pirataria de software mais ajuda do que prejudica as grandes corporações do setor, pois ela dificulta novos desenvolvedores a entrar nesse mercado. Logo, juridicamente, a restauração do papel das leis de propriedade intelectual pode tornar possível uma melhor proteção jurídica, bem como auxiliar a disseminar o acesso ao conhecimento, considerando a inovação tecnológica nesse mercado.

\section{Palavras-chave}

Direitos autorais; pirataria; propriedade intelectual; programa de computador.

\section{Abstract}

How does piracy influence the computer software market? This research aims to analyze the effects of piracy on both the major international software corporations and the small software developers. The theoretical framework is composed by the theories of living lawfully and the struggle for recognition. A qualitative analysis is achieved through the methodology of the rules of inference. The main results are that intellectual property laws ends up encouraging market monopoly rather than competitive innovation and that the software piracy helps rather than hinders the major software corporations, because it hampers the new computer software developers from entering this market. Therefore, from a legal perspective, restoring the role of the software intellectual property law may enable a better legal protection as well as help disseminate access to knowledge, as far as technological innovation in this market is concerned.

\section{Keywords}

Copyright; piracy; intellectual property; computer software. 


\section{INTRODUÇÃO}

O disseminado discurso de que a pirataria é a maior vilã das grandes corporações de software é tão difundido que passa a ser internalizado pela sociedade em geral, mas é pouco questionado e investigado em sua origem e em seus efeitos. A presente pesquisa visa investigar o fenômeno da pirataria de programas de computador por meio de estudo bibliográfico, de análise crítica da legislação e de dados fáticos concernentes ao tema para contestar essa compreensão padronizada.

Os referenciais teóricos adotados são o de viver plenamente a lei, de Zenon Bankowski, e o da luta por reconhecimento, de Axel Honneth, e têm essencial função de auxiliar na análise do tema pesquisado. A metodologia adotada parte da análise qualitativa de conteúdo, por vias de um processo válido de inferências, buscando tornar claro e conciso o processo de construção do conhecimento e de análise dos dados diretos.

Considerando-se a presença concomitante de grandes corporações e de pequenos desenvolvedores no mercado de programas de computador, o problema de pesquisa, que guia a investigação realizada, se estabelece no formato da seguinte pergunta: quais efeitos a pirataria produz na conjuntura do mercado de software? A partir dessa pergunta é possível investigar os impactos da pirataria sobre o comportamento desses agentes de mercado e sobre a efetividade dos direitos de propriedade intelectual aplicados ao software.

Para empreender essa investigação, os passos adotados serão os seguintes: no próximo capítulo serão elucidados a metodologia de pesquisa, o plano teórico adotado, os tipos de dados utilizados e a justificativa da seleção destes. O capítulo 2 será subdividido em três tópicos: o primeiro trata de uma revisão de literatura sobre as temáticas relacionadas da propriedade intelectual, do mercado de programas de computador, da pirataria de software e da legislação brasileira concernente ao tema. O segundo aborda a forma de coleta dos dados diretos analisados e o último tópico se dedica à discussão dos resultados, por meio da realização de inferências.

O objetivo é o de analisar os mercados brasileiro e norte-americano de software de sistemas operacionais, a partir de indicadores de ordem econômica e mercadológica, de modo a traçar a relação entre a pirataria, os direitos de propriedade intelectual e a inovação no setor. $\mathrm{O}$ foco da abordagem se dá pela análise dos efeitos da pirataria, especificamente no mercado de software, diante da relação dicotômica entre as grandes indústrias internacionais e os pequenos desenvolvedores locais desse setor.

Como resultado de pesquisa, os direitos de propriedade intelectual aplicados ao software não têm cumprido um papel de incentivo à inovação. Em termos empíricos, constatou-se que sequer a pirataria se revela como uma vilã das grandes corporações do setor. Assim, o estudo se justifica pela contestação do papel dos direitos de propriedade intelectual no campo dos programas de computador, considerando a proposta de inovação tecnológica nesse mercado. 


\section{i Percurso metodológico e plano teórico}

O método de pesquisa utilizado parte de uma análise qualitativa de conteúdo que possibilite o estabelecimento de um sistema legítimo de inferências. Tal conteúdo investigado é extraído tanto de forma direta, quanto indireta. Indiretamente se apresenta por via do levantamento de conteúdo documental e bibliográfico utilizado para investigar a relação entre os programas de computador e a pirataria. Já o conteúdo direto se delineia tanto pela análise legislativa quanto pela construção de um quadro de dados extraídos de fontes que tratam de aspectos centrais da pirataria no mercado de software.

Com relação aos dados diretos, estes serão abordados no próximo item. Trata-se dos indicadores do setor econômico relacionados à distribuição de renda, taxas de pirataria no âmbito do software, e dos índices dos sistemas operacionais ${ }^{1}$ mais utilizados nos países analisados pela pesquisa.

A análise adotada é do tipo qualitativa por traços de significação, segundo Babbie (2007). Nesta, a análise primeiramente se desdobra por consulta a conteúdo publicamente documentado sobre o tema da pirataria de software, estabelecendo-se hipóteses iniciais frente ao marco teórico. Após essa consulta, são coletados dados diretos que permitem assegurar ou reformular essas hipóteses iniciais. Por fim, visa-se estabelecer o questionamento e a reestruturação das normas legais, verificando-se eventuais incoerências entre o contraste da realidade fática, de um lado, e o ideal normativo, de outro.

O objetivo da análise qualitativa se completa por meio do método de realização de inferências, de cunho descritivo e causal. Conforme Epstein e King (2013), as inferências em si consistem em se valer de fatos conhecidos para alcançar fatos desconhecidos. Elas são descritivas quando utilizam os dados obtidos sobre um fenômeno para dar um salto qualitativo e compreender um fenômeno ainda mais amplo. São causais, por sua vez, quando utilizam-se de uma variável causal principal para investigar sua influência na variável causal dependente (EPSTEIN; KING, 2013).

O universo de análise do artigo está situado no contexto da pirataria de software de computador. Dessa maneira, as inferências do presente estudo são descritivas, de sorte que a investigação se pauta primeiramente pelo emprego de dados obtidos sobre a utilização de software do tipo sistema operacional e por meio do estudo da pirataria, para compreender sua ocorrência no âmbito brasileiro e norte-americano. O salto qualitativo ocorre pela compreensão dos traços básicos das influências globais da pirataria no software em geral, como um fenômeno amplo. Realizam-se também inferências causais, quando se utiliza o evento

1 Segundo Dhamdhere (2009), um sistema operacional é um tipo de software gerenciador de recursos de um computador, recursos tais como processador, memória e periféricos de entrada e saída, para atender às necessidades dos diferentes usuários. Exemplos de software de sistemas operacionais são o Microsoft Windows, o Mac OS e o GNU/Linux. 
específico das legislações de direito autoral, ou copyright, do software e dos indicadores econômicos e de pirataria - variáveis causais principais -, para investigar a real interferência destes elementos supracitados no mercado e na sociedade em geral - variáveis dependentes (EPSTEIN; KING, 2013).

O que se busca é investigar se as atuais medidas de combate à pirataria de software, sob os pressupostos de propriedade do direito autoral clássico, são realmente eficazes. Para tal investigação, há de se asseverar que, como em qualquer inferência, inexiste no presente estudo grau absoluto de certeza. Entretanto, isso de forma alguma torna a pesquisa inválida, uma vez que a evidência de como estes dados foram obtidos e explorados e as inferências que deles se realizam são elucidadas da maneira mais ampla e fidedigna quanto possível (EPSTEIN; KING, 2013).

\section{I O CONTEXTO DA UTILIZAÇÃo DOS DADOS}

Os dados deste estudo foram sistematizados no formato de quadro, para a sua melhor compreensão e facilidade de sistematização. Tal quadro se construiu a partir da extração e confluência de dados sobre os seguintes índices: os índices econômicos do Produto Interno Bruto (PIB) e da Renda Nacional Bruta (RNB), as taxas de pirataria e as estatísticas acerca da plataforma de sistema operacional mais utilizada em cada um dos dois países analisados.

Estes índices que compõem o Quadro 1 foram obtidos por meio de três fontes independentes: o PIB e a RNB foram extraídos diretamente da base de dados on-line ${ }^{2}$ do Banco Mundial, as taxas de pirataria foram extraídas a partir de relatórios especializados da BSA ${ }^{3}$ e os dados sobre qual a plataforma de sistema operacional mais utilizada e sua devida porcentagem foram obtidos por meio da base StatCounter. ${ }^{4}$ Todos os passos adotados e especificidades serão descritos em momento oportuno, no item 3.1: A coleta de dados e a criação do Quadro 1. E o presente tópico se dedica a justificar a utilização de cada um desses índices.

Dos países escolhidos, adotou-se o Brasil e os Estados Unidos para se estabelecerem patamares comparativos. O Brasil foi adotado por sua legislação autoral de software e por sua inserção proeminente no cenário da pirataria, ao passo que os Estados Unidos foram escolhidos por ser o país que apresenta as menores taxas de pirataria do mundo em 2013, segundo a BSA (2014), e também por ser o país berço de gigantes corporações multinacionais

2 Endereço eletrônico: <http://data.worldbank.org>.

3 BSA - The Software Alliance, organização mundial que visa a proteção dos direitos das indústrias de software.

4 Website: <http://gs.statcounter.com>. Serviço disponível apenas em inglês. Quanto ao uso de sistemas operacionais, são gerados sempre os sete sistemas operacionais mais utilizados de cada período escolhido. 
de software, como a Microsoft, a Apple, entre outras. O limiar temporal para todos os dados começa em 2010, ano em que estão disponíveis os primeiros dados sobre utilização de sistemas operacionais na base StatCounter e vai até o ano de 2013, cujos resultados foram publicados em 2014.

No que tange aos índices econômicos de PIB e de RNB, optou-se por suas consultas pelo seguinte motivo: ainda na fase de revisão da literatura, observou-se que a pirataria de software decorre, além de outros motivos, de um problema de altos preços dos produtos oficiais no mercado para países em desenvolvimento, como o Brasil. Essa constatação mais bem explicada no capítulo 2, pelas citações de Cosovanu (2006), Katz (2005), Tigre e Marques (2009) e Mizukami et al. (2011). Portanto, o PIB e o RNB são indicadores econômicos relevantes para estabelecer patamares mínimos das riquezas nacionais e, de forma genérica, a distribuição financeira de renda das populações nos países estudados.

Com relação aos dados da BSA, sobre os índices mundiais de pirataria no mercado de software, é importante destacar que existem críticas à metodologia do estudo. No campo dessas críticas se situam Karaganis (2011) e Mizukami et al. (2011), que afirmam a existência de limitação metodológica dos relatórios da BSA, pois estes relatórios consideram que uma cópia pirateada de software seria substituta do exemplar original no mercado, o que geraria perda econômica para as empresas e para a economia em geral.

Porém, os autores destacam que não existe evidência de que o usuário da cópia não licenciada optaria pela original se não houvesse pirataria, já que a versão licenciada geralmente tem alto preço. Além disso, salientam que a pirataria não poderia ser considerada necessariamente uma perda à economia local já que, da perspectiva do consumidor, haveria um processo de transferência de gastos do produto pirateado para outros bens de mercado (KARAGANIS, 2011; MIZUKAMI et al., 2011).

Da mesma forma, Tigre e Marques (2009) argumentam que não existe uma correlação necessária de que, se a pirataria fosse extinta, os consumidores de software falsificado em países em desenvolvimento, como o Brasil, estariam dispostos a comprar programas originais. O caminho seria inverso: esses consumidores não optariam por programas proprietários devido ao seu alto custo, o que implicaria uma diminuição no número total de usuários, licenciados ou não, do software.

Ressalta-se que essas críticas se dirigem sobretudo ao valor comercial das cópias pirateadas, dado que não foi utilizado nessa pesquisa. Quanto aos índices de pirataria, embora também existam críticas pela eventual oscilação dos últimos números (MIZUKAMI et al., 2011), eles foram empregados justamente por serem as principais estatísticas oficiais disponíveis da indústria de software, por terem regularidade de lançamento seguindo uma mesma metodologia e por serem avaliados no mundo todo em regime de cooperação com as agências locais (BSA, 2014). Ademais, como um dos objetivos da presente pesquisa é justamente o de investigar se a pirataria afeta as grandes corporações de software, a utilização de dados oficiais das próprias representantes das corporações, a BSA e a ABES, não 
subdimensionaria o problema, já que as associações possuem o discurso oficial contra a pirataria (ABES, 2014; BSA, 2014).

Por fim, os dados da plataforma StatCounter foram utilizados por se tratar de um serviço de monitoramento de estatísticas de acesso que está presente em mais de 2,5 milhões de sites parceiros, e conta com atualizações a cada 4 horas e processos regulares de revisão de qualidade (STATCOUNTER, 2014b). Assim, os dados fornecidos pela base permitem, entre outros temas, verificar quais são os sistemas operacionais de microcomputador com maiores índices de utilização em cada país. Esse dado é útil para viabilizar a análise acerca da existência de monopólio no setor de sistemas operacionais e do grau de inovação neste mercado.

\section{I.2 OS REFERENCIAIS TEÓRICOS ADOTADOS}

A fundamentação teórica da presente pesquisa parte do contexto de viver plenamente o direito, de Zenon Bankowski e da ideia de luta por reconhecimento, de Axel Honneth.

Segundo Bankowski (2008), viver plenamente o direito, pelo uso do raciocínio parabólico, significa estabelecer a constante interação entre o direito e o amor. O amor não é trabalhado pelo autor no sentido romantizado, mas sim como um mecanismo que exige a compreensão das particularidades do caso, enquanto a lei se configura como mecanismo para estabelecer padrões de regularidade e de ordem. Diante da constante e necessária interação entre esses dois ocorrem as chamadas explosões de atos de amor, as quais revelam o avanço das leis no tempo e espaço em razão da evolução das sociedades.

Utilizando o raciocínio parabólico imagine, por exemplo, um motorista de ônibus de uma empresa que recebe ordens restritas de dirigir em certo trajeto que leva a uma universidade. Ele pode parar apenas em pontos pré-estabelecidos que se encontram em intervalos regulares de 150 metros para o embarque e o desembarque de passageiros. Entretanto, em dado momento, ao realizar esse trajeto com o ônibus cheio de estudantes que teriam uma prova, o motorista se depara, a cerca de 50 metros do ponto final, com um congestionamento que deixa o trânsito totalmente parado. Caso aguarde o congestionamento cessar, o motorista fará com que todos os estudantes percam o horário da prova e, assim, resolve com a devida precaução abrir as portas do ônibus para que os mesmos possam caminhar e chegar a tempo para o exame.

Por essa situação percebe-se que o motorista teve de lidar com as tensões entre lei e amor e, pelas explosões de atos de amor, entendeu a necessidade de superar a lei no caso concreto. Caso o motorista sempre seguisse a lei, somente parando no ponto final, todos os estudantes seriam prejudicados e atrasariam ou perderiam sua prova, o que se configura como uma burocratização perversa. Em contrapartida, caso apenas seguisse os instintos do amor, pararia em qualquer situação e em qualquer lugar para atender às eventuais necessidades dos passageiros gerando, assim, um verdadeiro caos no processo de condução de passageiros e tornando o meio de transporte inviável e instável. Finalmente, por meio 
do pequeno exemplo, ilustra-se que viver plenamente a lei significa compreender qual o significado do direito, seja ele uma legislação, seja uma norma cotidiana e, para além disso, entender qual a aspiração por detrás da norma (BANKOWSKI, 2008).

O segundo marco teórico é o de luta pelo reconhecimento. Em Honneth (2003), a luta pelo reconhecimento no plano social é contextualizada em três níveis correlacionados: o do amor, o do direito e o da estima social. Pelo âmbito do amor, o indivíduo desenvolve sua autoconfiança por meio de um processo de liberdade própria, desenvolvido pelo confronto de sua individualidade no convívio com os demais integrantes da sociedade. O nível do direito é marcante, uma vez que estabelece para o indivíduo o autorrespeito. Nesse ambiente social integrado, tanto o comportamento próprio quanto o dos demais sujeitos encontram limitações na medida em que os valores consagrados no meio social são internalizados nas esferas subjetivas. Já o plano da estima social é marcado pela solidariedade, ponto em que o indivíduo encontra seu devido valor em sua participação e em sua cooperação na sociedade da qual faz parte.

A luta pelo reconhecimento acontece, porque perpassa a esfera unicamente subjetiva para contemplar a dos demais indivíduos conviventes no plano socializado. A luta constante nessas três esferas revela a necessidade de reconhecer não só as intersubjetividades em movimento, mas também o exercício da autonomia individual. Destarte, com as esferas individuais e coletivas integradas, dar-se-á respaldo e construir-se-á um plano social pulsante e integrado (HONNETH, 2003).

Viver plenamente o direito e travar a luta pelo reconhecimento são processos que também afetam a realidade informatizada. O software, o fenômeno da pirataria, e os direitos de propriedade intelectual necessitam de um enfoque que não passe nem pelo ponto de vista restrito da lei, sem sua devida fundamentação, nem pela perspectiva das esferas individuais, sem seu devido encaixe no plano comum do qual fazem parte. Dessa forma, é essencial partir desses planos teóricos para a compreensão e contestação dos fenômenos estudados e para o processo de realização de inferências.

\section{Desvendando A Pirataria de software E O CONTEXTO DA LEGislaÇÃo BRASILEIRA}

“A cópia ilegal não gera remuneração para que os autores invistam na própria melhoria dos programas. Toda a sociedade paga caro. A oferta de empregos diminui, o Estado deixa de arrecadar, o País fica com sua imagem comprometida no exterior. Além disso, as empresas estrangeiras, bem como as nacionais, não se sentem seguras para investir em tecnologia e no desenvolvimento de novos produtos. Resultado: atraso tecnológico, muitas vezes irrecuperável” (ABES, 2014). 
O trecho acima, retirado do portal online da ABES, ${ }^{\mathbf{5}}$ dedica-se à pirataria de software e reproduz o tratamento comum dado ao tema. Trata-se de uma abordagem de lógica binária e reducionista, sob o ponto de vista da violação dos direitos de propriedade intelectual. No entanto, para tentar empreender uma análise mais profunda sobre o fenômeno da pirataria e seu encaixe na atual sociedade digital, é necessário investigar para muito além das velhas assunções e da lógica repressiva por si só.

Assim, o caminho adotado no presente tópico é o da revisão de literatura de publicações que contribuam de forma crítica para a compreensão da temática estudada. Além disso, a revisão de literatura demonstra, em caráter exemplificativo, um padrão recorrente nas legislações de propriedade intelectual ao redor do mundo, corroborando o favorecimento às grandes corporações de software fechado.

Antes de se trabalhar com a pirataria, uma tarefa relevante que surge é a de estabelecer um significado para o termo. Embora essa não seja uma missão simples, Johns (2010) estabelece algumas diretrizes ao afirmar que a pirataria não possui um significado estático, puramente associado à violação de propriedade intelectual licenciada. O autor aduz que a doutrina clássica dos direitos de propriedade intelectual não foi a responsável por cunhar esse conceito já que, em termos empíricos, o movimento foi inverso: historicamente, os principais conceitos da propriedade intelectual, como o copyright, desenvolveram-se para tentar conter o fenômeno social da pirataria.

Desse modo e, ancorando-se na análise de um estudo oficial conduzido para a União Europeia, o pesquisador afirma que um bom ponto de partida para o estabelecimento de um conceito de pirataria seria: tudo aquilo que as indústrias do conhecimento desejarem ver protegido. Malgrado, na perspectiva do autor, esse seja um bom conceito, ele não é capaz de exaurir o significado do termo. Faz-se necessário, portanto, enxergar a pirataria como um conceito histórico e complexo, que passa por constantes evoluções e antecede a própria institucionalização dos conceitos de propriedade intelectual (JOHNS, 2010).

Com a evolução tecnológica, a ocorrência da pirataria passou a se tornar mais evidente no âmbito das mídias em geral. Karaganis (2011) aponta que a pirataria se refere, na verdade, a um problema mundial de preços, que cresce devido a fatores como: o alto preço das variadas mídias (como software ou DVD), a baixa renda local de países em desenvolvimento, a difusão da tecnologia e as rápidas mudanças na cultura e no consumo.

Como a pirataria afeta diferentes tipos de obras protegidas pelos direitos autorais, como músicas, livros ou produções audiovisuais (KARAGANIS, 2011), cabe ressaltar que sua análise na presente pesquisa é voltada para o âmbito do software. Essa abordagem setorizada se justifica pelas peculiaridades que os programas de computador possuem em relação

5 Associação Brasileira das Empresas de Software, website oficial: <http://www.abessoftware.com.br>. 
a outras obras protegidas pelo mesmo direito autoral. ${ }^{6}$ Entre essas especificidades, salientam-se dois elementos distintivos primordiais: o fato de o software possuir um código fonte ${ }^{7}$ e o fato de estar suscetível à ocorrência simultânea de dois efeitos estudados na literatura econômica, os efeitos de rede e de aprisionamento.

Sobre o código-fonte, ao desenvolver um software, o programador ou o detentor dos direitos autorais possui a opção de deixá-lo aberto, disponibilizando-o aos demais programadores, como ocorre com o software livre, ${ }^{8}$ ou fechado, retendo-o para si, como ocorre com o software proprietário da Microsoft Corporation. Da perspectiva jurídica, a importância dessa escolha reflete no tipo de licença autoral cabível.

Conforme Lemos (2005), se o código for aberto, a licença jurídica será do tipo copyleft. Esse tipo de licença é menos restritivo e possibilita a transparência da tecnologia do software, tornando-o disponível para verificação e até edição, sem prejuízo à titularidade autoral do desenvolvedor ou à exploração econômica do seu programa. Entretanto, se a opção for por fechar o código, o software será protegido via copyright e o conhecimento e a edição da tecnologia ali empregada ficam restritos ao detentor de seus direitos.

No que tange aos efeitos econômicos de rede e de aprisionamento, estão diretamente relacionados com a forma de gestão dos direitos autorais e com a pirataria de programas de computador.

Ao estudar a pirataria no domínio de economias emergentes, Cosovanu (2006) ressalta que os direitos de propriedade intelectual são dotados de irrelevância prática no que tange aos desenvolvedores locais de programas de computador. Essa irrelevância decorre do fato de que a pirataria não atinge os programas por eles desenvolvidos, mas sim o chamado software de prateleira (como sistemas operacionais, planilhas de texto, programas gráficos). Esses tipos de software, pertencentes a grandes corporações internacionais, grande parte norte-americanas, são vendidos por praticamente os mesmos preços que nos

6 A Lei n. 9.610/1998 elenca no âmbito dos treze incisos de seu artigo $7^{\circ}$ os vários tipos de obras intelectuais protegidas por seu escopo. A mero título exemplificativo citam-se os casos de textos de produções acadêmicas, literárias e artísticas (inciso I), as canções (inciso V), as fotos e pinturas (incisos VII e VIII) e o próprio software (inciso XII) (BRASIL, 1998a). Quanto ao software, contudo, possui ainda lei específica, a Lei n. 9.609/1998, para tratar de suas complexidades.

7 Segundo Lee (2006), o código-fonte é a linguagem de programação decifrável para que humanos compreendam e editem um programa de computador. Assim, é onde fica alocado o conhecimento de programação empregado no software.

8 Por uma questão de recorte metodológico do objeto da presente pesquisa, o software livre será abordado apenas no que tange à possibilidade de seu estabelecimento como opção de mercado ao software proprietário fechado. Para uma leitura mais detalhada no contexto brasileiro, como a legislação específica de software livre e sua situação de mercado, consultar Chein Feres e Oliveira (2016). 
Estados Unidos da América, mas em economias com populações em condições financeiras mais desfavoráveis.

Cosovanu (2006) argumenta que em países em desenvolvimento é praticamente inexistente a criação de software de prateleira por nacionais, tendo em conta uma espécie de divisão internacional do trabalho na indústria de software. Por este fenômeno as empresas de países em desenvolvimento, como a Índia, estudada pelo autor, participam em etapas mais básicas e menos compensadoras de criação e aperfeiçoamento de um software para as grandes corporações do ocidente.

Dessa maneira, nas economias emergentes, os mesmos tipos de software de prateleira dos países desenvolvidos são os mais usados, não obstante o seu alto preço local. Esse uso ocorre graças à pirataria, que desenvolve o papel de vilã indispensável, como porta de entrada do software de prateleira das grandes indústrias em mercados atrativos, como os de países em desenvolvimento (COSOVANU, 2006).

Ainda conforme o autor, é por essa porta de entrada que a pirataria tem a função de criar o primeiro efeito supracitado, o chamado network effect, ou efeito de rede. Este termo significa a valorização demasiada de um certo software devido à sua ampla utilização e ao grande número de usuários. A combinação da pirataria com esse efeito de rede gera uma maior gama de usuários do software e uma barreira à entrada de outros desenvolvedores no mercado concorrencial. O bloqueio ocorre, pois, quanto maior o número de pessoas que conhece um software, seja pirateado ou não, maior será a sua respectiva capacidade de influenciarem mais indivíduos a utilizá-lo, assim como também maior se tornará a familiaridade com esse programa. Como consequência, são menores as chances de troca desse software, dado que o processo envolveria custos não apenas financeiros, mas também de tempo e de disposição para o aprendizado de um programa não habitual (COSOVANU, 2006).

Tigre e Marques (2009) também observam a relevância do efeito de rede no caso da pirataria de software, sobretudo para o contexto de países em desenvolvimento. Ao citar Shapiro e Varian (1999), aqueles autores abordam o conceito de "feedback positivo" no uso de produtos pirateados. Ainda que o uso de uma cópia não licenciada do software fechado de grandes indústrias não gere receitas imediatas, o feedback ocorre ao colaborar no crescimento do número de usuários do programa e, assim, consolidar a empresa proprietária no mercado.

Ao pesquisar sobre as origens e as consequências da pirataria e sobre os impactos do efeito de rede, Katz (2005) observa que a falha na proteção do software por parte das grandes empresas e o consequente avanço da pirataria é, na verdade, uma estratégia de mercado. Essa estratégia funciona em três passos. Primeiramente, há uma intencional brecha na proteção dos programas para possibilitar a pirataria, pois ela permite a rápida disseminação do software e o seu consequente aumento de valor, pelo já abordado efeito de rede. Na medida em que cresce esse efeito de rede e os usuários se habituam ao software, seja original seja pirata, verificam-se as consequências do segundo efeito supracitado, o efeito lock in, ou de “aprisionamento". 
O efeito de aprisionamento decorre do fato de que os usuários comuns e as empresas ficam dependentes da tecnologia do software, que passa a se tornar essencial para as suas atividades. Por fim, uma vez que muitos usuários necessitem do software, mas muitos utilizam-se das versões piratas, é possível pressioná-los à regularização de suas versões. Esse processo de patrulha e regularização ocorre sobretudo no âmbito de empresas e governos, que têm uma imagem a zelar e cujos funcionários e servidores já se habituaram ao programa (KATZ, 2005).

Logo, essa estratégia progressiva, que começa com a pirataria e se utiliza dos efeitos de rede e de aprisionamento, acaba por se tornar uma barreira aos novos concorrentes no setor, levando as grandes indústrias ao monopólio de mercado em países em desenvolvimento. Esta é justamente a constatação de Tigre e Marques (2009), ao observarem que, caso a pirataria fosse inviabilizada pelas empresas, com o uso de tecnologias de controle, os usuários seriam forçados a deixarem de utilizar esses programas proprietários e a buscarem alternativas, como o software livre.

Ainda de acordo com Katz (2005), as justificativas formais das empresas para não aumentarem a segurança de seus programas e inviabilizarem a pirataria não são convincentes, ou não refletem os reais motivos para que essas corporações não invistam em proteção de software. Entre as justificativas mais recorrentes, ele destaca as seguintes: as más experiências das empresas em décadas atrás com proteção (a proteção do software era demasiada, o que atrapalhava ou burocratizava o acesso do próprio usuário), a rapidez da quebra de uma tecnologia de proteção nos tempos atuais (atualmente, mais hackers conseguem quebrar tecnologias de proteção de software) e os eventuais aborrecimentos que a tecnologia protetiva gera ao consumidor.

Em contrapartida, o autor rebate essas justificativas, chamando-as de senso comum. A burocratização na utilização do software não se justifica, pois as tecnologias atuais, como a criptografia, são bem mais eficientes e menos complicadas para os usuários comuns. Em relação aos hackers e sua capacidade de burlar esquemas de segurança, aduz que os prejuízos alegados com a pirataria, no mundo todo, estão em ordem de bilhões de dólares e, mesmo que uma tecnologia de proteção possa ser quebrada, ela pode salvar altas cifras das perdas alegadas pelas indústrias de software. Para ilustrar sua posição, Katz se utiliza da analogia de uma fechadura que protege algo valioso: não é porque ela possa ser aberta que uma pessoa deixará de trancá-la.

Por fim, mesmo os eventuais aborrecimentos das técnicas de proteção também não se justificam. O consumidor, que já está acostumado com a ideia e a necessidade de se proteger nos tempos atuais, de ameaças cibernéticas como vírus e outros, dificilmente reclamaria de uma tecnologia que fosse benéfica ao seu programa e ao seu computador (KATZ, 2005).

Como visto, o código-fonte e os efeitos de rede e de aprisionamento são elementos que denotam as nuances específicas dos impactos da pirataria para o setor de programas de computador. Ainda neste tópico, o que se segue é uma análise dos padrões legislativos que 
permitem verificar a forma pela qual a propriedade intelectual interage com a pirataria de software.

Mizukami et al. (2011) exploram o cenário da pirataria no Brasil e afirmam que esse problema, decorrente dos altos preços das mídias e da busca por acesso a bens intelectuais, pode ser visto por duas perspectivas: a de formalização de leis para proteção da propriedade intelectual e a de efetiva mudança no comportamento de consumo de tais bens.

No âmbito comportamental, afirmam que nem mesmo as legislações ou as medidas existentes contra a pirataria são capazes de influenciar a abstenção no uso de bens não licenciados. As iniciativas antipirataria existentes no Brasil, por exemplo, são em larga parte oriundas de campanhas privadas, financiadas pelo próprio setor privado. Além disso, elas geralmente se utilizam de táticas demagógicas e pouco educativas, como a sua associação ao crime organizado ou a sua comparação ao furto de bens tangíveis (MIZUKAMI et al., 2011). Karaganis (2011) explica que essas iniciativas são exercidas majoritariamente pelas grandes indústrias americanas de propriedade intelectual, que investem em advocacia, políticas antipirataria, lobby legislativo e outras ações políticas.

No plano legislativo, Mizukami et al. (2011) expõem que as grandes indústrias de criações intelectuais obtiveram êxito na aprovação de leis que asseguram o reforço dos direitos de propriedade intelectual. O caso do Brasil confirma a assertiva, pois as Leis de Direitos Autorais (Lei n. 9.6010/1998) e a de Software (Lei n. 9.609/1998) são legislações combativas à pirataria de programas de computador, estabelecendo penas ${ }^{9}$ que variam de 6 meses a até 4 anos e multa.

Entretanto, é diminuta a fiscalização e a aplicação dessas disposições de lei. Conforme Karaganis (2011), o judiciário brasileiro e de países em desenvolvimento não mobiliza de forma tão intensa o seu aparato para os direitos de propriedade intelectual, pois os níveis

9 “Art. 12. Violar direitos de autor de programa de computador:

Pena - Detenção de seis meses a dois anos ou multa.

$\S 1^{\circ}$ Se a violação consistir na reprodução, por qualquer meio, de programa de computador, no todo ou em parte, para fins de comércio, sem autorização expressa do autor ou de quem o represente:

Pena - Reclusão de um a quatro anos e multa.

$\S 2^{\circ} \mathrm{Na}$ mesma pena do parágrafo anterior incorre quem vende, expõe à venda, introduz no País, adquire, oculta ou tem em depósito, para fins de comércio, original ou cópia de programa de computador, produzido com violação de direito autoral.

$\S 3^{\circ}$ Nos crimes previstos neste artigo, somente se procede mediante queixa, salvo:

I - quando praticados em prejuízo de entidade de direito público, autarquia, empresa pública, sociedade de economia mista ou fundação instituída pelo poder público;

II - quando, em decorrência de ato delituoso, resultar sonegação fiscal, perda de arrecadação tributária ou prática de quaisquer dos crimes contra a ordem tributária ou contra as relações de consumo.

$\S 4^{\circ}$ No caso do inciso II do parágrafo anterior, a exigibilidade do tributo, ou contribuição social e qualquer acessório, processar-se-á independentemente de representação” (BRASIL, 1998). 
de pobreza e violência são elevados e o próprio aparelho judiciário já é em si caótico, com alto número de processos judiciais de lenta duração.

Outra questão de profunda importância no cenário legislativo de software é o longo período de exclusividade que uma empresa possui sobre o código-fonte de seu programa. A Lei n. 9.609/1998, que regula a proteção dos programas de computador no contexto brasileiro, estabelece o direito exclusivo do proprietário sobre o software fechado por 50 anos. ${ }^{10}$

A legislação nacional atualmente em vigência é oriunda de heranças de outras legislações e principalmente do Projeto de Lei n. 200/1995. Já em janeiro de 1996, à época da discussão sobre o período de proteção exclusiva, a previsão inicial do projeto de lei era de estabelecer o prazo de 25 anos, contudo, essa disposição não logrou êxito.

Alguns parlamentares já alertavam sobre os riscos de estabelecer um marco temporal alto, como o de 50 anos para os programas de computador. É o que pode ser observado em um pequeno trecho da fala do então deputado federal Inácio Arruda (à época do PCdoBCE) na Câmara, sobre o substitutivo que aumentava o tempo de exclusividade sobre o software, de 25 para 50 anos:

$\mathrm{O}$ artigo $2^{\circ}$ do substitutivo amplia a proteção ao detentor do programa de 25 para 50 anos. Este prazo é muito longo já que a indústria de informática é extremamente dinâmica e em apenas três anos um programa pode tornar-se obsoleto [...] cada vez mais, o nosso País se torna mais subalterno dos interesses externos, o que representa um prejuízo muito grande para o futuro do País. Era o que tinha a dizer (BRASIL, 1996).

Conforme o então deputado, o prazo de proteção se tornaria excessivo, haja vista a rápida defasagem dos programas de computador. Seu alerta, entretanto, não foi acolhido, tendo a Câmara aprovado a extensão do prazo para 50 anos, tal como hodiernamente se conhece, por 408 votos favoráveis contra 11 votos desfavoráveis e quatro abstenções (BRASIL, 1996).

Por fim, faz-se necessário entender que o plano dos programas de computador, gerido por leis como a legislação de software brasileira, exerce influência direta na realidade de mercado e no consumo de tais produtos, visto como na atualidade as tecnologias se inserem com fundamental importância na vida de cada um. às obras literárias pela legislação de direitos autorais e conexos vigentes no País, observado o disposto nesta Lei.

$[\ldots]$

$\S 2^{\circ}$ Fica assegurada a tutela dos direitos relativos a programa de computador pelo prazo de cinquenta anos, contados a partir de $1^{\circ}$ de janeiro do ano subsequente ao da sua publicação ou, na ausência desta, da sua criação" (BRASIL, 1998). 
Para Lessig (1999), o âmbito de existência dos programas de computador, chamado de ciberespaço, não se constitui em um mundo abstrato, pois sua existência não é excludente da dos tradicionais espaços físicos. O ciberespaço é produto de várias relações singulares que se desdobram ao mesmo tempo e que geram reflexos de natureza estrutural no mundo físico tal se conhece. Assim, discutir a atual esfera da proteção dos programas de computador é discutir importante fator integrante da vida real dos indivíduos brasileiros e do próprio mercado nacional.

Dessa forma, em Honneth (2003), o indivíduo constitui sua subjetividade e se relaciona com a intersubjetividade dos demais, construindo uma verdadeira luta pelo reconhecimento, que também ocorre no plano digital. Considerando os argumentos teóricos de Bankowski (2008), observa-se a necessidade de compreender a atual legislação pelas aspirações que a fizeram surgir, qual sejam a proteção do autor e o avanço tecnológico, contudo sem prejudicar ou privar a livre iniciativa e os membros da comunidade de acesso ao conhecimento.

Assim, a atual legislação incentiva o monopólio e inviabiliza o acesso legalizado a bens informatizados, prejudicando a comunidade em geral e os novos desenvolvedores de software por aspectos puramente econômicos. Logo, o marco legislativo brasileiro de software não cumpre com o seu papel elementar de proteção, pois falha substancialmente no incentivo amplo ao desenvolvimento e à criação de novas iniciativas no setor.

O pequeno fragmento da história da legislação de software brasileira, apresentado pelo contexto do Projeto de Lei n. 200/1995, serve para estimular uma análise sobre o atual contexto fático dos programas de computador no Brasil, como economia emergente. Antes de iniciar essa análise, que será feita com os dados diretos consultados no tópico 2.2, faz-se necessário contextualizar a forma de coleta destes.

\section{I A COlETA de dAdOS E A CRIAÇÃo do QuAdro I}

O processo de coleta de dados e a elaboração do Quadro 1 se desenvolveu pelos seguintes índices: o PIB, a RNB, as taxas de pirataria, a plataforma de sistema operacional mais utilizada e sua porcentagem de utilização. Esses índices se referem ao Brasil e aos Estados Unidos, no intervalo temporal de quatro anos, de 2010 até 2013. O objetivo do presente tópico é o de explicar o modo como cada um desses indicadores foi coletado.

O PIB trata da soma do que a economia nacional produziu, sem maiores deduções e foi retirado do website do Banco Mundial. Embora exista a disponibilização do idioma do site em português, os serviços acessados estão apenas disponíveis em língua inglesa. A coleta se deu da seguinte maneira: acessado o website do Banco Mundial, no campo data, foi digitada a expressão “GDP, PPP (constant 2011 international \$)”. 11

Termo equivalente do inglês para Produto Interno Bruto, por Paridade do Poder de Compra, em valores constantes do dólar internacional em 2011. Este tipo de índice foi adotado por ser o mais adequado 
O índice da Renda Nacional Bruta trata de uma distribuição per capita dos recursos nacionais, retirados valores que não pertencem exatamente à economia nacional, pois são lançados ao exterior. Esse dado foi retirado da mesma base, com a exceção do valor americano no ano de 2013, preenchido complementarmente. ${ }^{12}$ A sua coleta se deu da seguinte forma: no mesmo website foi digitado, no campo data, a expressão "GNI Per Capita, PPP (constant 2011 international \$)" ${ }^{13}$

As taxas de pirataria, por sua vez, foram obtidas segundo os relatórios da BSA (2012; 2014), sendo que o relatório publicado em 2012 foi adotado para coletar os índices referentes aos anos de 2010 e 2011 e o relatório publicado em 2014 foi utilizado para coletar os dados referentes ao ano de 2013. Com relação aos índices referentes ao ano de 2012, não há estatísticas oficiais produzidas pela BSA.

Por fim, os indicadores referentes à plataforma de sistema operacional (simbolizada pela sigla "SO") mais utilizada em cada um dos dois países foi coletado diretamente da base online $^{14}$ do site StatCounter. O processo de coleta foi o seguinte: no website do serviço, campo Stat, no subitem Platform, foi selecionada apenas a opção Desktop e no subitem Statistic foi selecionada apenas a opção Operating System.

Essas seleções significam que serão mostrados apenas os índices referentes ao software do tipo SO presentes em computadores de mesa, como computadores pessoais (PCs) ou

e comumente utilizado em análises socioeconômicas, como as do Programa das Nações Unidas para o Desenvolvimento (UNDP, 2014). Segundo o Banco Mundial (WORLD BANK, 2014, tradução nossa), esse índice se baseia no dólar internacional com o mesmo poder de compra sobre o Produto Interno Bruto que o dólar americano possui nos Estados Unidos. É calculado a partir da soma do valor bruto adicionado por todos os produtores residentes na economia nacional junto dos impostos sobre produtos, retirados os subsídios não inclusos no valor do produto. O cálculo ocorre sem a dedução da depreciação dos ativos ou a degradação dos recursos naturais.

12 Como inexistiam dados referentes ao ano de 2013 para os Estados Unidos na base do Banco Mundial, o quadro foi completado seguindo exatamente o mesmo índice para os Estados Unidos no ano de 2013, existente no Relatório de Desenvolvimento Humano 2014 (UNDP, 2014).

13 Termo equivalente do inglês para Renda Nacional Bruta per capita, por Paridade do Poder de Compra, em valores constantes do dólar internacional em 2011. Este tipo de índice foi adotado por ser o mais adequado e comumente utilizado em análises socioeconômicas, como as do Programa das Nações Unidas para o Desenvolvimento (UNDP, 2014). Conforme o Banco Mundial (WORLD BANK, 2014, tradução livre), o índice se funda na soma dos valores adicionados por todos os produtores residentes no país junto de quaisquer impostos sobre os produtos, exceto subsídios. Não são incluídos na avaliação da produção a saída de receitas líquidas de renda primária para o exterior, como gastos com empregados e rendas de propriedades. O dólar internacional segue, novamente, o mesmo poder de compra sobre a Renda Nacional Bruta que o dólar americano possui nos Estados Unidos.

14 Website: <http://gs.statcounter.com>. Serviço disponível apenas em inglês. Quanto ao uso de sistemas operacionais, são gerados sempre os sete sistemas operacionais mais utilizados de cada período escolhido. 
notebooks (excluindo-se tablets, consoles de videogame ou celulares). No campo Period, selecionando o subitem Daily, os intervalos temporais escolhidos são sempre de $1^{\circ}$ de janeiro até 31 de dezembro do ano investigado. Um gráfico é gerado para os valores de cada ano, conforme o país selecionado (Brasil ou Estados Unidos) por meio do campo Region.

Dessa forma, foi gerado um gráfico sobre os sistemas operacionais mais utilizados de $1^{\circ}$ de janeiro até 31 de dezembro de 2010, para o Brasil, e outro, no mesmo período, para os Estados Unidos e, assim, sucessivamente para os anos de 2011, 2012 e 2013, coletando-se os valores apresentados. O modo de exibição escolhido, à direita do gráfico, é o Bar, pois os resultados são demonstrados numa constante do período selecionado.

Avaliou-se, primeiramente, os valores entre cada marco temporal, sobre qual a plataforma mais utilizada de software de sistema operacional. Um exemplo: no ano de 2010 (de $1^{\circ}$ de janeiro até 31 de dezembro) no Brasil, estes são os sete sistemas operacionais mais utilizados: Windows XP, com 69,47\% dos usuários brasileiros, Windows 7, com 18,44\%, Windows Vista, com 10,04\%, GNU/Linux, com 0,94\%, MacOSX, com 0,74\%, Windows 2003, com 0,11\% e Windows 2000, com 0,09\% dos usuários de sistema operacional. Outros sistemas operacionais contabilizam $0,17 \%$, já que o gráfico identifica a porcentagem apenas dos sete tipos de software mais utilizados.

Os dados acima exemplificados foram sistematizados da seguinte forma no Quadro 1: para o ano de 2010 no Brasil, a plataforma de sistema operacional mais utilizada foi o Microsoft Windows, com um total de 98,15\% dos usuários brasileiros (somando-se os $69,47 \%$ do Windows XP, mais 18,44\% do Windows 7, mais 10,04\% do Windows Vista, mais $0,11 \%$ do Windows 2003 , mais $0,09 \%$ do Windows 2000). Portanto, todas as versões do Sistema Operacional Microsoft Windows foram somadas, por pertencerem ao mesmo fabricante e proprietário, a Microsoft.

Assim, em cada um dos 4 anos nos países analisados, todas as versões do programa Microsoft Windows (seja o Windows 2000, o Windows 2003, o Windows XP, o Windows Vista, o Windows 7 ou o Windows 8) que vigoraram no Top 7 de sistemas operacionais foram somadas, independentemente de que tipo fossem. Apresentadas todas essas etapas e esclarecidos os índices, a discussão dos dados será realizada no tópico a seguir, no formato de inferências. 
Quadro 1 - PIB, RNB e os Índices de Pirataria e Sistemas Operacionais no BRASIl E NOS ESTADOS UNIDOS

\begin{tabular}{|c|c|c|c|c|c|c|}
\hline PAÍS & ANO & ÍNDICES & & & & \\
\hline & & $\begin{array}{l}\text { PIB EM BILHÕES } \\
\text { (2011 PPC US\$) }\end{array}$ & $\begin{array}{l}\text { RNB PER CAPITA } \\
\text { (2011 PPC US\$) }\end{array}$ & $\begin{array}{l}\text { TAXA DE } \\
\text { PIRATARIA }\end{array}$ & $\begin{array}{l}\text { PLATAFORMA } \\
\text { DE SO MAIS } \\
\text { UTILIZADA }\end{array}$ & $\begin{array}{l}\text { PORCENTAGEM } \\
\text { DE UTILIZAÇÃO } \\
\text { DO WINDOWS }\end{array}$ \\
\hline \multirow[t]{4}{*}{ BRASIL } & 2010 & 2.741 & 13.794 & $54 \%$ & $\begin{array}{l}\text { MICROSOFT } \\
\text { WINDOWS }\end{array}$ & $98,15 \%$ \\
\hline & 2011 & 2.816 & 14.031 & $53 \%$ & $\begin{array}{l}\text { MICROSOFT } \\
\text { WINDOWS }\end{array}$ & $97,96 \%$ \\
\hline & 2012 & 2.845 & 14.103 & - & $\begin{array}{l}\text { MICROSOFT } \\
\text { WINDOWS }\end{array}$ & $96,97 \%$ \\
\hline & 2013 & 2.916 & 14.282 & $50 \%$ & $\begin{array}{l}\text { MICROSOFT } \\
\text { WINDOWS }\end{array}$ & $96,62 \%$ \\
\hline \multirow[t]{4}{*}{ EUA } & 2010 & 15.252 & 49.849 & $20 \%$ & $\begin{array}{l}\text { MICROSOFT } \\
\text { WINDOWS }\end{array}$ & $84,45 \%$ \\
\hline & 2011 & 15.533 & 50.864 & $19 \%$ & $\begin{array}{l}\text { MICROSOFT } \\
\text { WINDOWS }\end{array}$ & $82,16 \%$ \\
\hline & 2012 & 15.965 & 51.713 & - & $\begin{array}{l}\text { MICROSOFT } \\
\text { WINDOWS }\end{array}$ & $82,99 \%$ \\
\hline & 2013 & 16.265 & 52.308 & $18 \%$ & $\begin{array}{l}\text { MICROSOFT } \\
\text { WINDOWS }\end{array}$ & $79,95 \%$ \\
\hline
\end{tabular}

Fonte: BSA, 2012; BSA, 2014; STATCOUNTER, 2014a; UNDP, 2014; WORLD BANK, 2014a; WORLD BANK, 2014b.

\subsection{CONSIDERAÇÕES SOBRE O QUADRO I E O PROCESSO DE INFERÊNCIAS}

Diante do que é exposto no Quadro 1, mesmo com o crescimento da economia brasileira, demonstrado a partir da evolução do PIB nos últimos quatro anos, observa-se, ainda, uma má distribuição dos recursos e consequente desigualdade social. Essa observação decorre da 
RNB per capita nacional, que no ano de 2013 era de 14.282 dólares, se comparada com a americana, de 52.308 dólares no mesmo período. O Brasil, como país em desenvolvimento, ainda tem de enfrentar problemas na distribuição de suas riquezas, enquanto nos EUA vê-se uma economia desenvolvida, com maior distribuição de renda para a população e um PIB cerca de 5,5 vezes maior do que o brasileiro, considerando o idêntico intervalo temporal.

As taxas de pirataria de programas de computador, por sua vez, são inversamente proporcionais ao desenvolvimento econômico e à distribuição de riquezas dos dois países. Esse dado acompanha as constatações de Cosovanu (2006), Mizukami et al. (2011) e de Karaganis (2011) acerca do problema de altos preços em países com economias modestas. Enquanto os Estados Unidos, com uma economia desenvolvida, possuem as menores taxas de pirataria de software do mundo (de 18\% no ano de 2013), o Brasil, em ascensão econômica, possui taxas de software pirateado que, embora em declínio, ainda são altas (na faixa de 50\% no ano de 2013).

A questão que surge é: como países com diferenças socioculturais e econômicas como Brasil e Estados Unidos possuem padrões legislativos e de preço para tais tipos de software relativamente similares? Uma população, como a brasileira, haveria de usar um software devidamente legalizado de seu alto custo e, ainda, respeitar a legislação de software no padrão norte-americano diante do notável menor poder aquisitivo daquela população? Pelos dados, a resposta imediata é negativa, uma vez que um em cada dois tipos de software operacional brasileiro é pirateado.

Em se tratando do campo de software de SO, observa-se claramente o monopólio da plataforma Microsoft Windows. Monopólio este mais acentuado em uma economia emergente como a brasileira e, embora em menor escala, ainda existente nos Estados Unidos. No ano de 2013, a utilização do Microsoft Windows alcançava expressivas taxas de 96,62\% no mercado nacional, enquanto nos Estados Unidos era de 79,95\%. A observação de tais índices deve levar ainda em conta que, diante do já exposto, os programas pirateados - um em cada dois no Brasil - em economias emergentes são predominantemente software de prateleira, como o próprio Microsoft Windows.

Os índices vão ao encontro do argumento de Katz (2005), de que as grandes corporações de software têm maior tolerância fática com a pirataria em países em desenvolvimento, visando justamente ganharem mercado, obterem o chamado "efeito de rede", criarem a dependência tecnológica e inibirem a ascensão de concorrentes. Assim, para o autor, a política oficial antipirataria tem, tão somente, a função de legitimar o alto preço cobrado pelo software legalizado, enquanto a postura prática é de tolerância.

Essa afirmação pode ser corroborada pela estrutura teórica aqui escolhida, dado que o processo de luta por reconhecimento demanda uma análise bem informada das escolhas às quais estão sujeitos os indivíduos de uma dada sociedade.

Nesse contexto, há, sem dúvida, uma falha no processo de comunicação e de interação entre sujeitos, culminando numa lógica de alienação e de comprometimento da autonomia 
no que se refere tanto à correta e sincera compreensão da legislação existente, quanto à internalização de condutas moralmente legítimas no contexto das instituições. Cabe constatar, a partir dos dados expostos, que a legislação existente serve apenas aos interesses das grandes empresas de software, no sentido de aumentar o poder de mercado e criar situações de captação de consumidores.

Cosovanu (2006) também chega à conclusão similar, de que a pirataria na verdade beneficia as grandes corporações, ao ponto de comparar a situação do software com a dos medicamentos. Enquanto a diferenciação de preços de medicamentos das grandes corporações é comum em âmbito mundial, muito de acordo com o papel dos governos de subsidiá-los para as suas populações frente às especificidades de cada país, no plano do software inexiste tal necessidade. A regulação agressiva não é necessária, uma vez que a própria lei e as políticas de conscientização das grandes corporações contra a ilegalidade são postas em prática somente após o crescimento e a conquista de mercado por meio da pirataria.

Da mesma forma, Tigre e Marques (2009) também verificam o impacto negativo que a pirataria de programas de computador gera para a inovação e a possibilidade de oferta de novos tipos software no setor. O feedback positivo das grandes corporações, obtido por meio do efeito de rede gerado pela pirataria, funciona como um propulsor de domínio mercadológico, em detrimento de outros desenvolvedores de programas que desejam se lançar ao mercado, como os de software livre.

Esse efeito de rede gera distorções agudas no processo de autonomia dos consumidores, assim como desrespeita os direitos individuais dos cidadãos de uma comunidade. A partir dessa lógica de naturalização da exploração econômica do software, as grandes empresas comprometem os mecanismos naturais de oferta e de escolha pelo melhor produto, gerando, sempre que lhes for interessante, uma dinâmica de alienação e de sujeição do consumidor de países em desenvolvimento, dominando o mercado de software e inviabilizando concorrentes.

A partir dos dados do Quadro 1 e dos referenciais teóricos levantados, são realizadas duas inferências, de caráter descritivo e causal (EPSTEIN; KING, 2013). A primeira inferência é a de que a legislação autoral aplicada a software se desdobra em um mero aparato de garantia de monopólio. Trata-se de uma inferência causal, pois se utiliza dos desdobramentos da Lei n. 9.609/1998 (variável principal) no plano mercadológico de programas de computador do Brasil (variável dependente). Além disso, baseia-se em dados do setor de software do tipo de sistemas operacionais para compreender traços gerais do mercado de software como um todo.

A fundamentação da inferência se dá tanto pelo norte teórico da luta pelo reconhecimento (HONNETH, 2003), quanto pelos elementos fáticos supracitados.

Para Honneth (2003), o papel do direito é elementar ao constituir a luta pelo reconhecimento, ao lado do amor e da estima social. Contudo, no plano informatizado brasileiro, o indivíduo, ao não utilizar um programa devidamente legalizado, concebe a pirataria 
como uma prática naturalizada pela sociedade e pelo mercado, sendo influenciado pelos traços restritivos das legislações de propriedade intelectual aplicadas ao software.

O sujeito de mercado se vê alienado e subjugado a uma lógica econômica automatizada que o utiliza como instrumento de aumento de poder, assim como lhe nega a possibilidade do pleno conhecimento sobre as escolhas referentes ao melhor sistema operacional para si. A relação entre direito e estima social, na perspectiva de Honneth (2003), aplica-se nesse caso no sentido de avaliar, a partir dos dados levantados, uma relação de causalidade perversa: os consumidores e desenvolvedores de software se veem cativos de uma legislação e de um processo de mercado que alienam sua liberdade de escolha e de oferta de programas de computador.

Dessa maneira, observa-se que a Lei n. 9.609/1998, por meio do incentivo exclusivo ao copyright e do estabelecimento do período de 50 anos para a manutenção de tal direito, se desdobra em um instrumento legalizado para a garantia do monopólio das grandes corporações. Ao mesmo tempo, dadas as altas taxas de pirataria, vê-se que a proibição e as sanções penais não possuem aplicabilidade concreta no contexto brasileiro. Ocorre, pois, um descrédito geral em relação ao marco legislativo de software. Os prejudicados são a própria comunidade e o mercado, reféns de uma luta de todos contra todos, em que as grandes corporações agem contra seus concorrentes, numa lógica de mercado deturpada.

A segunda inferência é de que a mera criminalização da pirataria, em função da proteção dos direitos de propriedade intelectual, por si só, não resolve o problema e tampouco incentiva a inovação. Essa inferência é também causal, pois se utiliza dos dados consultados, sobretudo os relativos aos índices de pirataria e de utilização de sistemas operacionais, para verificar o impacto da pirataria (variável principal) sobre o mercado e a inovação (variáveis dependentes).

O fundamento dessa inferência ocorre pela teoria de viver plenamente a lei (BANKOWSKI, 2008) e também pelos dados diretos coletados.

Bankowski (2008) aponta a necessidade de entender o sentido por detrás da lei, para então, se necessário, superá-la. A legislação brasileira de software foi criada com o intuito de dar proteção ao desenvolvedor de programas de computador e de incentivar a inovação tecnológica no setor. Entretanto, no âmbito fático, a prática da pirataria e o monopólio mercadológico que se instauraram nacionalmente, como observado pelo setor de sistemas operacionais, conduzem a uma lei que não condiz com sua aspiração.

Para entender o sentido e a aspiração de uma legislação, Bankowski (2008) expõe que a mera repressão pode não ser a solução para evitar um problema concreto. Muitas vezes, a aspiração da legislação pode ser alcançada por meio de uma ação política específica no sentido de conter o comportamento desviante. Diante desse ponto, não basta somente o estabelecimento e a manutenção de uma lei que criminaliza a conduta da pirataria, já que o fenômeno ocorre em altas taxas. É preciso romper com a lógica restritiva e monopolista de mercado hoje existente e buscar alternativas e incentivos ao criador de diferentes tipos de software nacionais. 
Os direitos de propriedade intelectual, por meio das atuais legislações de países em desenvolvimento, como a Lei n. 9.609/1998, apenas contribuem para o cenário de falta de incentivo e de impedimento aos criadores de software, impossibilitados de desenvolverem e expandirem seus programas devido ao domínio mercadológico global das grandes corporações. Faz-se, pois, necessário estabelecer iniciativas e também incentivos a longo prazo para o desenvolvimento nacional de software, sobretudo os relativos a software livre, que como visto, estimulam a inovação e a concorrência ao mesmo tempo em que possibilitam a disseminação do conhecimento ali empregado.

Ressalte-se que o argumento aqui exposto não visa ao mero estabelecimento de uma lei em favor do software livre e em detrimento do software proprietário. O que se defende é o estabelecimento de medidas integradas, como capacitação e incentivo à indústria nacional de software como forma de estímulo à concorrência e à inovação, almejando a contenção de monopólios. A finalidade da ressignificação do tema é de, portanto, impulsionar tecnologias legitimamente nacionais e criar um mercado próprio competitivo, fornecendo alternativas ao consumidor.

Dessa maneira, o fenômeno da pirataria tem agido como uma espécie de Robin Hood às avessas no que tange aos agentes desenvolvedores de programas de computador: retirando dos pequenos desenvolvedores nacionais a possibilidade de se estabelecerem no mercado e cooperando com as grandes corporações que monopolizam o setor.

Não se discute aqui a colaboração e a importância de grandes corporações, como a Microsoft, para o setor mundial de software. O que se pretende discutir, entretanto, é o domínio de mercado dessas corporações sob a óptica da inovação e da liberdade de oferta no setor. Também não se trata aqui de avaliar do ponto de vista da correção jurídica a estratégia no âmbito subjetivo da empresa, pois esta segue as regras próprias do mercado. Ademais, não se argumenta que programas proprietários de código fechado possuam menor importância do que programas de código aberto, como o de software livre, no plano de mercado. O que se aponta é que não existe um cenário profícuo ao ingresso de novos tipos de software e à competição nesse setor. Enquanto a pirataria agir em prol de grandes desenvolvedores e inibir o crescimento de novas iniciativas, o cenário será justamente de monopólio, de restrição de conhecimento e de pouco incentivo às inovações.

Logo, constata-se que o papel dos direitos de propriedade intelectual, como no caso do software, precisa ser reavaliado diante das atuais conjunturas em que se encaixa e necessita de uma nova propositura nos moldes da era da comunicação. A mera criminalização da pirataria no âmbito legislativo não terá qualquer poder para solucionar o problema de inovação no setor. Governos, legislações e iniciativas que visem incentivar criações e promover os novos desenvolvedores de programas de computador têm, dessa forma, papel fundamental para fomentar a diversidade e o avanço tecnológico para toda a comunidade global. Essa é a verdadeira luta pelo reconhecimento e a lei plena de sentido no plano informatizado que se deve buscar. 


\section{CONSIDERAÇÕES FINAIS}

Esta pesquisa dedicou-se a investigar teórica e empiricamente o fenômeno da pirataria no mercado de programas de computador. Por meio da metodologia de análise qualitativa de dados buscou-se, utilizando-se de inferências descritivas e causais, realizar uma interpretação crítica do atual panorama brasileiro e mundial sobre o tema e investigar seus desdobramentos no plano social e mercadológico.

O conteúdo bibliográfico, documental e legislativo, bem como os dados e indicadores investigados revelaram novas e importantes nuances sobre o setor e foram analisados sob os referenciais teóricos do viver plenamente a lei e da luta pelo reconhecimento, propostos respectivamente a partir de Zenon Bankowski e de Axel Honneth.

Averiguou-se que a pirataria de programas de computador afeta os chamados "software de prateleira”. Ao contrário do que é comumente disseminado pelas grandes indústrias, do ponto de vista fático, a pirataria acaba por auxiliá-las. Por meio dessa prática, essas corporações, sobretudo as norte-americanas, têm efetivado a sua inserção e manutenção em economias em desenvolvimento, como a brasileira. Diante da pirataria e dos chamados efeitos de rede e de aprisionamento, os tipos proprietários de software aumentam seu valor e se popularizam de tal forma que, muito além de conquistar o mercado, estabelecem-se como vias de mão única, dificultando a concorrência.

Por meio da verificação do monopólio no setor de sistemas operacionais, tanto no Brasil quanto nos Estados Unidos, e da ineficácia da legislação diante dos altos níveis de pirataria no primeiro país, verifica-se que as próprias legislações nacionais de software reforçam estas estruturas monopolistas e não colaboram para a diversidade no setor.

Por fim, a pirataria deve, sim, ser combatida, mas porque consiste em um instrumento de manutenção do status quo do mercado de software. Nesse contexto, a propositura de incentivos aos pequenos desenvolvedores e criadores de programas de computador é de extrema relevância para o crescimento tecnológico de países em desenvolvimento, porém deve ser auxiliada por uma legislação que apresente alternativas para o setor e também por iniciativas governamentais que promovam a capacitação dos agentes. Somente por meio de uma distribuição justa de oportunidades é que os direitos de propriedade intelectual resgatarão sua verdadeira função, a de promover o desenvolvimento tecnológico e o acesso de todos ao conhecimento. 


\section{NOTA DE AGRADECIMENTO}

A pesquisa conta com o apoio do Conselho Nacional de Desenvolvimento Científico e Tecnológico (CNPq), da Coordenação de Aperfeiçoamento de Pessoal de Nível Superior (Capes) e da Pró-Reitoria de Pesquisa (PROPP) da UFJF.

\section{REFERÊNCIAS}

ABES. Propriedade Intelectual: pirataria de software - prejuízos da pirataria. Associação Brasileira das Empresas de Software. Disponível em: <http://www.abessoftware.com.br/propriedade-intelectual/saiba-maissobre-pirataria-de-software>. Acesso em 2 out. 2014.

BABBIE, Earl. The practice of social research. 11. ed. Belmont: Thomson Wadsworth, 2007.

BANKOWSKI, Zenon. Vivendo plenamente a lei. Rio de Janeiro: Elsevier Brasil, 2008.

BRASIL. Discussão, em turno único, do Projeto de Lei n. 200-A, de 1995, que "Dispõe sobre a proteção da propriedade intelectual de programas de computador, sua comercialização no país, e dá outras providências". Diário da Câmara dos Deputados. Luís Eduardo (Presidente da Câmara), Brasília, n. 11, ano LI, jan. 1996.

Lei n. 9.610, de 19 de fevereiro de 1998. Altera, atualiza e consolida a legislação sobre direitos autorais e dá outras providências. 1998a. Disponível em: <http://www.planalto.gov.br/ccivil_03/ leis/L9610.htm>. Acesso em: 20 ago. 2013.

Lei n. 9.609, de 19 de fevereiro de 1998. Dispõe sobre a proteção da propriedade intelectual de programa de computador, sua comercialização no país, e dá outras providências. 1998b. Disponível em: <http:/ /www.planalto.gov.br/ccivil_03/leis/19609.htm>. Acesso em: 20 ago. 2013.

BSA. Shadow market: 2011 BSA Global software piracy study. The Software Alliance, 9. ed., mai. 2012. Disponível em: <http://globalstudy.bsa.org/2011/downloads/study_pdf/2011_BSA_Piracy_StudyStandard.pdf $>$. Acesso em 15 Set. 2013.

BSA. The compliance gap: BSA Global Software Survey. The Software Alliance, jun. 2014. Disponível em: <http://globalstudy.bsa.org/2013/downloads/studies/2013GlobalSurvey_Study_en.pdf>. Acesso em: 1 jul. 2014. 
CHEIN FERES, Marcos Vinício; OLIVEIRA, Jordan Vinícius. Softwares livres e governo: um filete de água no moinho digital. Revista Quaestio Iuris, Rio de Janeiro, v. 9, n. 2, p. 620-636, 2016.

COSOVANU, Catalin. Open source software in Eastern Europe and other emerging markets: The moral alternative to piracy? Journal of Internet Law, v. 9, p. 3-14, jan. 2006.

DHAMDHERE, Dhananjay M. Operating systems: a concept-based approach. 1. ed. New York: McGraw-Hill, 2009.

EPSTEIN, Lee; KING, Gary. Pesquisa empírica em direito: as regras de inferência. Tradução Fabio Morosini et al. São Paulo: Direito GV, 2013. Disponível em: <http://hdl.handle.net/10438/11444>. Acesso em: 28 mar. 2017.

HONNETH, Axel. Luta por reconhecimento: a gramática moral dos conflitos sociais. São Paulo: 34, 2003. 296 p.

JOHNS, Adrian. Piracy: The intellectual property from Gutenberg to Gates. Chicago: University of Chicago Press, 2010.

KARAGANIS, Joe. Chapter 1: Rethinking piracy. In: KARAGANIS, Joe (Ed.). Media piracy in emerging economies. Social Science Research Council, 2011. Disponível em: <http://piracy.ssrc.org>. Acesso em: 3 jun. 2014.

KATZ, Ariel. A network effects perspective on software piracy. University of Toronto Law Journal, v. 55, p. 155 , maio 2005.

LEE, Jyh-An. New perspectives on public goods production: Policy implications of open source software. Vanderbilt Journal of Entertainment and Technology Law, v. 9, n. 1, 2006. Disponível em: <http://ssrn.com/abstract=963491>. Acesso em: 15 jul. 2015.

LEMOS, Ronaldo. Direito, tecnologia e cultura. Rio de Janeiro: FGV, 2005.

LESSIG, Lawrence. The law of the horse: What cyberlaw might teach. Harvard Law Review, v. 113, n. 2, p. 501-549, 1999. Disponível em: <http://www.jstor.org/stable/1342331>. Acesso em: 30 set. 2012.

MIZUKAMI, Pedro M.; CASTRO, Oona; MONCAU, Luiz F.; LEMOS, Ronaldo. Chapter 5: Brazil. In: KARAGANIS, Joe (Ed.). Media piracy in emerging economies. Social Science Research Council, 2011. Disponível em: <http://piracy.ssrc.org>. Acesso em 3 jun. 2014. 
STATCOUNTER. Top 7 desktop operating systems. StatCounter global stats, 2014a. Disponível em: $<$ http://gs.statcounter.com>. Acesso: em 21 set. 2014.

. Frequently asked questions. StatCounter global stats, 2014b. Disponível em: <http:// gs.statcounter.com/faq\#methodology >. Acesso em: 21 set. 2014.

TIGRE, Paulo Bastos; MARQUES, Felipe Silveira. Apropriação tecnológica na economia do conhecimento: inovação e propriedade intelectual de software na América Latina. Economia e Sociedade, n. 18, v. 3, p. 547566, 2009.

UNDP. Human development report 2014. Sustaining Human Progress: Reducing vulnerabilities and building resilience. Published for the United Nations Development Programme, 2014. Disponível em: <http://hdr.undp.org/en/content/human-development-report-2014>. Acesso em: 25 set. 2014.

WORLD BANK. Gross domestic product converted to international dollars using purchasing power rates GDP, PPP (constant 2011 international \$). 2014a. Disponível em: <http://data.worldbank.org/ indicator/NY.GDP.MKTP.PP.KD>. Acesso em: 20 set. 2014.

Gross national income per capita converted to international dollars using purchasing power parity rates - GNI per capita, PPP (constant 2011 international \$). 2014b. Disponível em: <http://data.worldbank.org/indicator/NY.GNP.PCAP.PP.KD>. Acesso em: 19 set. 2014.

Marcos Vinício Chein Feres

Doutor em Direito Econômico. Professor Associado da Faculdade de Direito da Universidade Federal de JuIZ de Fora (UFJF). Pesquisador de Produtividade PQ2/CNPQ.

mvcheinagmail.com

Jordan Vinícius de Oliveira

Bolsista DS/CAPES de Mestrado. Bacharel em Direito pela Universidade Federal de Juiz de Fora e Mestrando em

DiREITO E INOVAÇÃO PELA MESMA INSTITUIC̣ÃO.

jordan-viniciusahotmail.com 
ROBIN HOOD ÀS AVESSAS: SOFTWARE, PIRATARIA E DIREITO AUTORAL : 94

Daniel Domingues Gonçalves

Graduado em Direito e Mestre pelo programa de Mestrado em Direito e InovaÇão (2016) da Faculdade de Direito dA Universidade Federal de JUIz de Fora. daniel-domingues-glahotmail.com 